\title{
Left ventricular hypertrophy in chronic kidney disease
}

\section{Sushanth Kumar, Jayakumar Jeganathan, Lingaiah Miryala}

Department of Medicine, Kasturba Medical College, Mangalore, Manipal University, Karnataka, India

Address for the Correspondence: Dr. Jayakumar Jeganathan, Department of Medicine, Kasturba Medical College, Mangalore (Manipal University), Karnataka - 575 003, India.

E-Mail: jaypsj@gmail.com

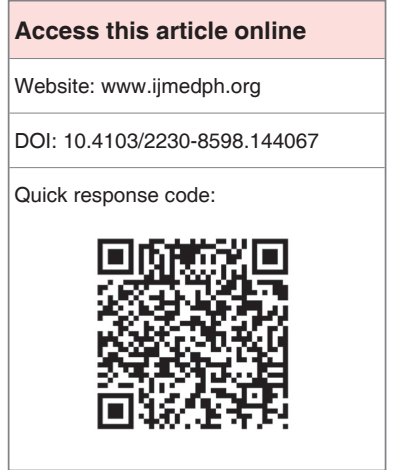

Introduction: Cardiovascular disease is a major cause of death in patients with chronic kidney disease (CKD). Mortality due to cardiovascular events is ten to twenty times greater than in general population. Left ventricular hypertrophy (LVH) is an independent predictor of mortality in chronic kidney disease patients. There are only a few studies which have looked at cardiovascular disease in Indian chronic kidney disease patients. Materials and Methods: This was a cross-sectional study of 100 consecutive chronic kidney disease patients in the nephrology department of our hospital. They were divided into mild, moderate and severe chronic kidney disease. The various parameters were then compared between these three groups using the Tukey's test. A $P$ value $<0.05$ was considered significant. Results: Out of the 100 patients, 69 had LVH. In the severe disease category, 39 patients $(88.63 \%)$ had LVH. In the moderate group, 18 patients (51.42\%) had LVH. In the mild group, 12 patients (57.14\%) had LVH. Only anemia was found to correlate with the presence of LVH. Conclusion: A significant number of CKD patients had LVH and the highest numbers of LVH were found in the severe CKD group.

Key words: Anemia, cardiovascular disease, chronic kidney disease, left ventricle hypertrophy, prevalence

\section{INTRODUCTION}

Cardiovascular disease is a major cause of death in patients with chronic kidney disease (CKD). According to literature the mortality due to cardiovascular events is ten to twenty times greater than in general population. ${ }^{[1]}$ Left ventricular hypertrophy $(\mathrm{LVH})$ is an independent predictor of mortality in CKD patients. ${ }^{[2]}$ Though there are many studies on cardiovascular disease in CKD patients, there are few studies which have looked at cardiovascular disease in Indian CKD patients. Datta in a study in Chennai estimated the prevalence of $\mathrm{LVH}$ to be around $78 \%$ in CKD patients. ${ }^{[3]}$ Hence, we undertook this study to look at LVH, an important marker of cardiovascular disease in CKD patients in south western part of India.

AIM: To study the prevalence of LVH in CKD patients and to correlate LVH with the degree of CKD.

\section{MATERIALS AND METHODS}

This was a cross-sectional study. A sample size of 95 was estimated by calculating with $80 \%$ confidence level and $80 \%$ power. A total of 106 consecutive CKD patients who fulfilled the inclusion criteria were included in the study after obtaining an informed consent. Out of them, six were lost to followup and they were excluded from the study. The study was approved by the local ethics committee.

\section{Inclusion criteria}

CKD patients as defined by National Kidney Foundation's K/DOQI (Kidney Disease Outcome Quality Initiative). ${ }^{[4]}$

\section{Exclusion criteria}

Patients diagnosed to have cardiovascular diseases like valvular heart disease and congenital heart disease. 
All subjects underwent a detailed history and physical examination. The following investigations were done for all the patients. Complete hemogram, serum creatinine, urine routine, ultrasound of the abdomen, serum sodium, potassium, calcium, phosphorus, electrocardiogram and echocardiography. CKD was classified as mild [glomerular filtration rate $(\mathrm{GFR})>60 \mathrm{ml} / \mathrm{min}$ per $1.73 \mathrm{~m}^{2}$ ], moderate (GFR: $30-60 \mathrm{ml} / \mathrm{min}$ per $1.73 \mathrm{~m}^{2}$ ) and severe (GFR < 30 $\mathrm{ml} / \mathrm{min}$ per $\left.1.73 \mathrm{~m}^{2}\right) \cdot{ }^{[4]}$ The GFR was calculated using the method that was given by Modification of Diet in the Renal Disease study group. ${ }^{[5]}$ Echocardiography: Measurements were performed using two-dimensional guided M-mode as recommended by American society of echocardiography. ${ }^{[6]}$ Left ventricular mass was calculated using the Devereux- modified method. ${ }^{[7]}$ Left ventricular mass index (LVMI) was calculated by dividing the left ventricular mass by body surface area. LVH was defined when LVMI exceeded $134 \mathrm{~g} / \mathrm{m}^{2}$ and $110 \mathrm{~g} / \mathrm{m}^{2}$ for men and women, respectively. ${ }^{[8]}$

Statistics: The CKD patients were divided into mild, moderate and severe categories. The various factors were then compared between these three groups using Tukey's test, which is the test used for intergroup comparisons. A $P$ value of $<0.05$ was taken as significant.

\section{RESULTS}

There were 33 female and 67 male patients. All the patients in the study belonged to the age group of 41-80 years. Most of the patients i.e., 41 patients belonged to the age group of 61-70 years. As shown in Table 1, maximum number of patients belonged to the severe CKD group. Out of the total 100 patients, 69 patients had LVH. In the severe CKD group, 39 patients (88.63\%) had LVH. In the moderate CKD group, 18 patients $(51.42 \%)$ had LVH. In the mild CKD group, 12 patients (57.14\%) had LVH. Table 2 shows the comparison of various parameters between the mild, moderate and severe CKD patients. Statistically significant differences were observed only for hemoglobin and serum creatinine values. Hemoglobin was significantly lower in the severe CKD group when compared to the moderate and mild categories. Serum creatinine was significantly higher in the severe CKD group when compared to the moderate and mild CKD groups. There was no statistically significant difference seen in the age, blood pressure and serum calcium between the three categories of CKD patients.

\section{DISCUSSION}

There are many risk factors for LVH in CKD patients. Anemia, hypertension, extra-cellular fluid expansion, arterio-venous fistulas and abnormalities of calcium phosphate homeostasis are some of the common mechanisms described. ${ }^{[9]}$ Zocalli et al. had shown a $50 \%$ mortality risk and more than $85 \%$ cardiovascular event risk at 3 years in the patients who had significant increase in left ventricular mass while undergoing dialysis. ${ }^{[10]}$ In our study, we found LVH to increase with the severity of CKD. In the severe CKD group, 88.63\% had LVH. Similar observations were noted by Paoletti et al., who found

\begin{tabular}{|c|c|c|}
\hline \multirow[t]{2}{*}{ Severity of CKD* } & \multicolumn{2}{|c|}{ Left Ventricular Hypertrophy } \\
\hline & Present (No.) & Absent (No.) \\
\hline Mild & 12 & 9 \\
\hline Moderate & 18 & 17 \\
\hline Severe & 39 & 5 \\
\hline Total & 69 & 31 \\
\hline
\end{tabular}

*CKD: Chronic kidney disease

\begin{tabular}{|c|c|c|c|c|}
\hline \multirow[t]{2}{*}{ Characteristics } & \multicolumn{3}{|c|}{ Chronic Kidney Disease } & \multirow[t]{2}{*}{$P$ Value } \\
\hline & Severe (a) & Moderate (b) & Mild (c) & \\
\hline $\begin{array}{l}\text { Creatinine } \\
(\mathrm{mg} / \mathrm{dl})\end{array}$ & $10.1 \pm 3.9$ & $4.2 \pm 0.7$ & $2.3 \pm 0.3$ & $\begin{array}{l}a \text { vs } b<0.001 \\
a \text { vs } c<0.001 \\
b \text { vs } c<0.05\end{array}$ \\
\hline Age (years) & $59.2 \pm 10.1$ & $60.1 \pm 7.7$ & $63 \pm 7.5$ & $\begin{array}{l}\text { a vs } b<0.05 \\
\text { a vs } c<0.05 \\
b \text { vs } c<0.05\end{array}$ \\
\hline $\begin{array}{l}\text { Hemoglobin } \\
(\mathrm{gm} \%)\end{array}$ & $11.5 \pm 0.1$ & $13.1 \pm 0.2$ & $13.8 \pm 0.3$ & $\begin{array}{l}\text { a vs } b<0.001 \\
a \text { vs } c<0.001 \\
b \text { vs } c<0.05\end{array}$ \\
\hline $\begin{array}{l}\text { Systolic blood } \\
\text { pressure }\end{array}$ & $134 \pm 17.55$ & $133.4 \pm 16.5$ & $131.6 \pm 15.9$ & $\begin{array}{l}\text { a vs } b<0.05 \\
\text { a vs } c<0.05 \\
b \text { vs } c<0.05\end{array}$ \\
\hline $\begin{array}{l}\text { Diastolic blood } \\
\text { pressure }\end{array}$ & $86.4 \pm 7.8$ & $88 \pm 6.8$ & $85.6 \pm 7.9$ & $\begin{array}{l}\text { a vs } b<0.05 \\
\text { a vs } c<0.05 \\
b \text { vs } c<0.05\end{array}$ \\
\hline $\begin{array}{l}\text { Serum calcium } \\
(\mathrm{mg} / \mathrm{dl})\end{array}$ & $8.4 \pm 0.9$ & $8.8 \pm 0.8$ & $8.9 \pm 1.2$ & $\begin{array}{l}\text { a vs } b<0.05 \\
\text { a vs } c<0.05 \\
b \text { vs } c<0.05\end{array}$ \\
\hline
\end{tabular}

a steady increase in the LVH as the renal dysfunction progressed during the predialysis stage of CKD. In their study they found that $70 \%$ to $80 \%$ of the severe CKD patients had LVH before the initiation of dialysis. ${ }^{[1]}$ In our study, statistically significant difference was seen only with the hemoglobin values which were found to decrease as the severity of CKD progressed. However, the blood pressure and the serum calcium values of the various degrees of CKD did not vary significantly. But a study done in Chennai found that the severity of anemia and hyperparathyroidism correlated well with the severity of $\mathrm{LVH}^{\left[{ }^{[2]}\right.}$ Londen $e$ al. who followed up a cohort of patients on hemodialysis for 5 years found that a $10 \%$ decrease in left ventricular mass resulted in $28 \%$ decrease in mortality risk from cardiovascular causes. ${ }^{[13]}$ Hence, early identification and treatment aimed at regressing the $\mathrm{LVH}$ can result in better outcomes in CKD patients. This is important as LVH by itself is known to predispose to ischemic heart disease, arrhythmias and congestive cardiac failure. ${ }^{[14]}$

\section{Limitation}

In order to see the exact relation between factors such as blood pressure, anemia, age, calcium and LVH in CKD patients, a study with a larger sample size would be needed. 


\section{CONCLUSION}

LVH was seen in a significant number of CKD patients. The proportion of people who developed LVH kept increasing with the severity of CKD even though there was no significant increase in the blood pressure.

\section{REFERENCES}

1. Locatelli F, Bommer J, London GM, Martin-Malo A, Wanner C, Yagoob M, et al. Cardiovascular disease determinants in chronic renal failure: Clinical approach and treatment. Nephrol Dial Transplant 2001;16:459-68.

2. Meyer KB, Levey AS. Controlling the epidemic of cardiovascular disease in chronic renal disease: Report from the National Kidney Foundation Task Force on cardiovascular disease. J Am Soc Nephrol 1998;9 (12 Suppl):S31-42.

3. Datta S, Abraham G, Mathew M, Somasundaram H, Muralidharan TR, Moorthy $\mathrm{A}$, et al. Hyperparathyroidism with left ventricular hypertrophy hypertrophy in chronic kidney disease patients. J Assoc Physicians India 2006;54:699-703.

4. K/DOQI clinical practice guidelines for chronic kidney disease: Evaluation, classification, and stratification. Am J Kidney Dis 2002;39 (2 Suppl 1):S1-266

5. Levey AS, Bosch JP, Lewis JB, Greene T, Rogers N, Roth D. A more accurate method to estimate glomerular filtration rate from serum creatinine: A new prediction equation. Modification of Diet in Renal Disease study group. Ann Intern Med 1999;130:461-70.

6. Sahn DJ, DeMaria A, Kisslo J, Weyman A. Recommendations regarding quantitation in M-mode echocardiography: Results of a survey of echocardiographic measurements. Circulation 1978;58:1072-83.

7. Devereux RB, Alonso DR, Lutas EM, Gottlieb GJ, Campo E, Sachs I, et al. Echocardiographic assessment of left ventricular hypertrophy: Comparison to necropsy findings. Am J Cardiol 1986;57:450-8.

8. Devereux RB. Detection of left ventricular hypertrophy by M- mode echocardiography. Anatomic validation, standardization, and comparison to other methods. Hypertension 1987;9(2 pt 2):I19-26.

9. Glassock RJ, Pecoits-Filho R, Barberato SH. Left ventricular mass in chronic kidney disease and ESRD. Clin J Am Soc Nephrol 2009;4(Suppl 1):S79-91.

10. Zoccali C, Benedetto FA, Mallamaci F, Tripepi G, Giacone G, Stancanelli B, et al. Left ventricular mass monitoring in the follow-up of dialysis patients: Prognostic value of left ventricular hypertrophy progression. Kidney Int 2004;65:1492-8.

11. Paoletti E, Bellino D, Cassottana P, Rolla D, Cannella G. Left ventricular hypertrophy in nondiabetic predialysis CKD. Am J Kidney Dis 2005;46:320-7.

12. Datta S, Abraham G, Mathew M, Somasundaram H, Muralidharan TR, Moorthy A, et al. Hyperparathyroidism with left ventricular hypertrophy hypertrophy in chronic kidney disease patients. J Assoc Physicians India 2006;54:699-703.

13. London GM, Pannier B, Guerin AP, Blacher J, Marchais SJ, Darne B, et al. Alterations of left ventricular hypertrophy in and survival of patients receiving hemodialysis: Follow up of an interventional study. J Am Soc Nephrol 2001:12:2759-67.

14. Ha SK, Park HS, Kim SJ, Park CH, Kim DS, Kim HS. Prevalence and patterns of left ventricular hypertrophy in patients with predialysis chronic renal failure. J Korean Med Sci 1998;13:488-94.

How to cite this article: Kumar S, Jeganathan J, Miryala L. Left ventricular hypertrophy in chronic kidney disease. Int J Med Public Health 2014;4:364-6.

Source of Support: Nil, Conflict of Interest: None declared. 